\title{
Impasse teórico da historiografia segundo Emília Viotti da Costa
}

Antônio David ${ }^{I}$

\section{A}

DIALÉTICA invertida e outros ensaios, da historiadora e professora emérita da Universidade de São Paulo Emília Viotti da Costa, merece ser lido com entusiasmo não só por historiadores, mas por todos que se dedicam a pesquisar e escrever sobre a História.

Produzidos em um intervalo de quarenta anos e versando sobre temáticas diversas - do problema dos degredados no povoamento do Brasil no período colonial ao movimento operário na América Latina no século XX, passando pelo moderno tráfico de escravos e pela influência francesa em São Paulo no século XIX -, os nove artigos nele reunidos possuem uma marcada unidade, no sentido forte do termo.

Seu pano de fundo reside na "ruptura epistemológica" ou no "impasse teórico" (p.11) que marcam a conjuntura na qual foram produzidos. Neles, a autora toma parte naquela que é a polêmica central das ciências humanas nas últimas décadas: nas palavras da autora, o "deslizamento progressivo de um momento estruturalista que privilegia a necessidade para um momento antiestruturalista que dá ênfase para a liberdade" (p.12), sendo esse último identificado à chamada Nova História.

No fundo, é a História o tema por excelência do livro. É a própria autora quem informa, na breve apresentação, que a coletânea expressa a "constante preocupação" de reconstruir o processo histórico pelo qual "os homens e mulheres fazem a história, embora não a façam em condições por eles escolhidas, pois atuam sobre uma realidade que já encontram definida pelos antepassados" (p.7). A alusão à célebre frase registrada em $O$ 18 Brumário de Luís Bonaparte, de Karl Marx, não é gratuita, como se verá nas linhas a seguir.

\section{Dois grupos dentro da esquerda}

Tendo dominado a historiografia contemporânea, o embate entre estruturalismo e antiestruturalismo não é circunscrito a essa disciplina, e as recorrentes menções a Sartre ao longo da coletânea não deixam dúvida sobre as afinidades intelectuais da autora (p.11, 18-21, 161, 217). Em última instância, essas duas correntes de pensamento constituem uma forma contemporânea de uma antiga querela, qual seja, a "tensão entre liberdade e necessidade" (p.11). Não é essa a questão por excelência para Agostinho, Calvino ou o idealismo alemão? só para citar alguns.

A autora busca as raízes históricas da divisão da historiografia entre esses dois grupos. Olhando para a história social do trabalho, onde a Nova História teria florescido com maior vigor (p.16), a autora constata que

o declínio numérico do proletariado e as dificuldades, senão impossibilidade, de criar uma consciência de classe levaram à redefinição das estratégias políticas de transformação social e simultaneamente à busca de novos paradigmas historiográficos orientados para o estudo da política do cotidiano. (p.23-4) 
Nas páginas 26 e 27, a autora elenca sumariamente elementos estruturais e conjunturais que, segundo ela, teriam "forçado a redefinição da prática e da teoria, da política e da historiografia". Para Costa, teria sido "dentro desse quadro, extremamente complexo e que varia de uma sociedade para outra, que se constituiu a nova História" (p.27).

Ao contrário do que se poderia supor, Costa sustenta que os debates entre "estruturalistas" e "antiestruturalistas" ou culturalistas não refletem conflitos entre marxistas e não marxistas. Ela argumenta que "ambas as tendências se encontram dos dois lados" e que "o debate contemporâneo que parece estar dividindo os historiadores procede em grande parte de conflitos dentro das próprias esquerdas" (p.161).

\section{Dialética invertida}

Não são poucos os momentos do livro em que a autora reconhece os méritos da Nova História. Segundo Costa, essa corrente de pensamento "contribuiu para reformular nossa percepção da história da classe operária na América Latina" (p.166). "Na nova historiografia" - argumenta Costa - "os trabalhadores aparecem como sujeitos da História em vez de objetos", e conclui: "Essa revisão que amplia de forma significativa o nosso conhecimento é devida em grande parte a historiadores que abandonaram as análises 'estruturalistas' tradicionais" (p.168).

Erguendo-se contra os equívocos do estruturalismo, a Nova História teve o mérito de colocar no centro da agenda historiográfica aspectos da realidade antes negligenciados ou mesmo esquecidos, reduzidos a epifenômenos, ligados à subjetividade e à experiência. Todavia, os méritos dessa grande corrente de pensamento não são suficientes para isentá-la de severas críticas. Costa é categórica quando se impõe a necessidade de fazer um juízo sobre cada um dos dois lados em disputa: "tanto uma postura quanto a outra me parecem igualmente equivocadas" (p.10).

Situando o embate no interior da dialética (p.11), Costa nota a ocorrência do que para ela seria uma inversão, a saber, o deslizamento de uma posição antidialética para outra posição antidialética (p.12$3,17,23)$ : "No meu entender, tanto as abordagens tradicionais hoje submetidas a crítica quanto as novas posturas são profundamente antidialéticas", de modo que, segundo a autora, "nenhuma [das duas posturas] faz jus à complexidade da dialética e da teoria da práxis" (p.13).

No que precisamente consiste a inversão? Tanto uma como outra "postulam uma separação artificial entre objetividade e subjetividade (ou liberdade e necessidade) esquecendo que uma está implicada na outra" (p.13). Conclui a autora: "porque a historiografia tradicional negligenciara, erroneamente, a subjetividade dos agentes históricos (transformando-a num epifenômeno), a nova historiografia fez desta o centro de sua atenção" (p.14).

Com isso, passou-se "simplesmente de um tipo de reducionismo a outro" (p.13). Para a autora, "ao reducionismo econômico substituiu-se um novo tipo de reducionismo: cultural ou linguístico, tão insuficiente quanto o anterior [...]. A um tipo de reificação opôs-se outro" (p.13). Em suma,

de um processo dedutivo, não dialético, $[\ldots]$ passou-se a um processo indutivo que jamais se alça ao nível teórico, e que quando muito se funda 
na esperança de que a acumulação de dados e monografias venha um dia a permitir a elaboração de uma teoria. (p.13-4)

Privilegiando "o acidental, o imprevisível, o inesperado, o irracional, o espontâneo, chegando-se ao ponto de se negar pura e simplesmente a existência do processo histórico" (p.14), abandonando "qualquer esforço de totalização" (p.13), grande parte dos trabalhos localizados na Nova História teriam caído no mesmo erro de seus adversários.

\section{Beco sem saída}

Tal inversão teria, segundo Costa, levado a historiografia a um verdadeiro beco sem saída (p.24). Reduzindo-se a exercício ou puramente estético e retórico ou meramente acadêmico, a historiografia corre o risco de servir ao propósito oposto daquele a que se visa (p.11): "o que potencialmente pode significar uma emancipação também pode facilmente se transformar num beco sem saída, pois é difícil posicionar-se numa História arbitrária, caótica, sem sentido nem direção" (p.15).

Ao abordar particularmente a história do trabalho, Costa adverte que, "sem uma visão mais ampla”, a nova história do trabalho, "em vez de representar um salto para a frente, pode facilmente se transformar numa história da vida $\mathrm{CO}^{-}$ tidiana, um gênero muito em moda na década de 1950, com conotações profundamente conservadoras" (p.173).

No que exatamente consiste o risco? Citando Schneider, Costa argumenta que muitos dos estudos locais e regionais "que se justificam em nome de dar VOZ aos oprimidos e preencher os pontos de silêncio do discurso oficial" acabam por desembocar "numa compilação não crítica e assistemática de detalhes, cuja relevância nunca é questionada, um cemitério de fontes, um repositório de curiosidades" (p.24). Ora, ao não perguntar sobre a relevância dos detalhes que se compila,

tudo se transforma em subjetividade, a do agente histórico e a do historiador, tudo fica uma questão de opinião. Nesse contexto, tudo se relativiza, faltam critérios para separar o relevante do irrelevante, o certo do errado, e torna-se inviável a formulação de um método histórico. (p.116)

Como se vê, a coletânea carrega a marca da conjuntura na qual os textos foram produzidos. Costa compreende haver no momento em que escreve "uma tendência conservadora bastante forte na historiografia, da qual os próprios historiadores que a praticam nem sempre chegam a ter consciência” (p.210, 218). Em face dessa tendência, a professora emérita da USP declara de maneira assertiva: "minha vida tem sido uma recusa permanente da posição conservadora, que no Brasil significa a perpetuação de uma sociedade imensamente desigual e injusta" (p.210). Note-se, porém, que esse mesmo compromisso Costa reconhece na origem da Nova História (p.113). Ela chega a argumentar que a Nova História, tal como se constituiu, seria "um momento necessário que a longo prazo pode ter como resultado a produção de uma nova História e uma nova prática mais eficaz" (p.24).

\section{Necessidade de uma nova síntese}

Se, como vimos, a Nova História perde-se "sem uma visão mais ampla" (p.173), convém indagar: no que consistiria a ampliação do campo de visão? Noutros termos: se, para Costa, a Nova História teria procedido à “inversão dos 
postulados da historiografia dos anos 1960, em vez de integrá-los numa síntese mais rica" (p.11), que postulados teriam sido invertidos? Costa argumenta: "meu objetivo é mostrar que as abordagens que se apresentam hoje como alternativas são muito mais eficazes quando se fundem num enfoque dialético mais amplo que permite ver no episódio o ponto de encontro de várias determinações conjunturais e estruturais" (p.117, grifo nosso).

No entanto, segundo Costa, "ao repudiar formas de abordagem tradicionais, os historiadores hoje" teriam perdido de vista o ponto de encontro entre os três níveis de análise mencionados: "As análises abandonam os níveis estruturais para se concentrar no nível das conjunturas e dos episódios, ao mesmo tempo que negligenciam as práticas não discursivas para focalizar as práticas discursivas e as ideologias, conferindo-lhe frequentemente total autonomia" (p.114-5).

A proposta de Costa vai ao encontro do esforço de historiadores para os quais a historiografia só pode ser concebida como totalização a partir de um jogo de escalas (Jacques Revel) que combina os níveis estrutural, conjuntural e episódico. Se a vaga antiestruturalista teria procedido à “inversão dos postulados da historiografia dos anos 1960, em vez de integrá-los numa síntese mais rica” (p.11), a crítica por si anuncia a saída. O objetivo explícito da autora é o de propor uma síntese entre os dois grupos em litígio (p.11, 25, 174).

A leitura da coletânea deixa ver que tal proposta não é algo impossível, tampouco inédito. Ao longo da coletânea, Costa faz menção a um não pequeno número de historiadores que, segundo ela, teriam conseguido estabelecer a síntese por ela defendida. Williams, Thompson,
Ginzburg, Davis, Schneider, Ludtke, Bergquist, James e de Shazo, Winn, Konish e Mericle são alguns nomes mencionados (p.12, 15, 23-4, 160, 161-2, 168-9, 172-3). Todavia, o diagnóstico feito pela autora é de que predominava a inversão antidialética no meio historiográfico.

Enfim, se a Nova História compreende "uma tendência saudável para corrigir o excesso contrário" (p.169), caberia ao historiador, sustenta Costa, preservar essa tendência. Para ela,

o momento favorece uma nova síntese que evite todas as formas de reducionismo e reificação, sejam eles econômicos, linguísticos ou culturais, uma síntese que não perca de vista a articulação entre microfísica e macrofísica do poder, que reconheça que a subjetividade é ao mesmo tempo constituída e constituinte, uma síntese enfim que seja centrada na teoria da práxis enriquecida pelas novas experiências e que leva a uma nova historiografia e a uma nova estratégia (que permita coordenar os vários movimentos sociais sem retirar-lhes a autonomia), e que a partir de uma reflexão sobre o passado e o presente prepare os caminhos do futuro. (p.28)

\section{O lugar das ideias}

A posição assumida por Costa não parece deixar dúvida de que, não obstante historicamente determinadas (p.117, $127,133)$, as ideias não podem ser encaradas como mero epifenômeno, como se tornou comum entre autores estruturalistas em meados do século passado (p.14). As ideias não são inteiramente autônomas, mas possuem autonomia relativa em relação às estruturas sociais. Ao historiador convém examinar a natureza dessa relação, ou seja, as condições his- 
tóricas sobre as quais nascem e operam certas ideias em cada período histórico.

Trata-se de uma orientação que tem afinidade com a leitura de Marx proposta por um insuspeito comentador: Schumpeter. Segundo o economista austríaco,

Marx não sustentou que religiões, metafísica, escolas de arte, ideias éticas e vontades políticas fossem redutíveis a motivos econômicos ou algo sem importância. Ele tentou apenas revelar as condições econômicas que as moldam e sobre as quais surgem e desaparecem. (Schumpeter, 1951, p.11)

Dito isso, causam certa estranheza algumas passagens da coletânea, nas quais a formulação parece pender para um estruturalismo que a própria autora critica, ou cuja crítica corrobora. Assim, no ensaio "O tráfico de escravos - uma lição sobre colonialismo", Costa afirma que "os colonos tinham de fazer acrobacias mentais e retóricas para racionalizar a ganância e justificar a exploração dos outros" (p.56), e que os portugueses "tiveram de arrumar outro jeito de justificar o tráfico de escravos" quando depararam com povos não muçulmanos (p.65), a ponto de chegarem, em um dado momento, a uma situação de "flagrante contradição com sua teologia" (p.77).

A autora vai além, sustentando que "os portugueses sempre encontravam uma justificativa teológica para suas guerras e ataques contra os africanos" (p.72) e que "a teoria da guerra justa fornecia aos portugueses os argumentos de que precisavam para legitimar seus atos" (p.74). Costa cita Oliveira, para quem "a salvação era só um pretexto" e que "se não fosse pelo interesse nos ganhos, os portugueses não iriam à África" (p.76).
A tese central do ensaio reside na ideia de processo autônomo: "[os reis] queriam lucrar sem pôr em risco suas almas e com o devido respeito à teologia, mas, assim como os reis africanos, eles também haviam iniciado um processo que não conseguiam controlar" (p.75). Note-se em particular o argumento de que, "desde o princípio, a lógica do lucro entrara em conflito com as intenções cristãs e humanitárias" (p.76, grifo nosso), pressupondo, com isso, que a verdade do processo pode ser encontrada já em seu princípio, estando ali presente de maneira oculta. O tempo trataria de revelá-la.

Finalmente, Costa chega à seguinte conclusão sobre o lugar da justificação nos processos históricos:

[...] funcionando como ideologia legitimadora, o cristianismo colocara certos limites às práticas coloniais que sancionava. Mas, por sancionar essas práticas e por fornecer aos colonizadores as justificativas morais para seus empreendimentos, o cristianismo deixou de ser capaz de prevenir a ascensão de interesses entrincheirados que terminaram por desconsiderar as restrições morais da teologia cristã e acabaram jogando a lógica da conversão religiosa na lixeira da História. (p.79)

Não teria a autora caracterizado nessas passagens de maneira demasiado instrumental e teleológica as ideias que operam como justificativa teológica?

Dúvida semelhante suscita o ensaio "Escravos: imagens e realidade". Aqui, contrapondo atitudes de senhores de escravos norte-americanos e brasileiros, a autora afirma que, ao contrário desses, "os norte-americanos do século XIX tinham de justificar a instituição escravista para o mundo e também para si mesmos. 
Eles encontraram uma boa desculpa na caracterização do negro como criança" (p.84, grifo nosso).

Para se ter dimensão do ponto para o qual queremos chamar a atenção, convém notar a ocorrência de alguns verbos no ensaio, na mesma linha da passagem acima transcrita: ter de; sentir-se obrigado a; precisar; poder (p.86, 90, 92, 1034). Tais verbos não sugerem que as ideias ocupam o lugar de epifenômeno? - exatamente o que a autora quer evitar.

Segundo Costa, a elite brasileira, por sua vez, "tomou cuidado ao escolher os aspectos da ideologia liberal que se encaixariam em sua realidade e serviriam a seus interesses” (p.87). À luz do que a própria autora sustenta ao longo da $\mathrm{co}^{-}$ letânea, cabe indagar se essa é uma formulação conveniente, a saber, que a elite teria escolhido sua ideologia, como se os agentes históricos assumissem essa ou aquela ideia de maneira deliberadamente instrumental.

\section{Referência}

COSTA, E. V. da. A dialética invertida e outros ensaios. São Paulo: Editora Unesp, 2014.

SCHUMPETER, J. A. Ten great economists from Marx to Keynes. Oxford: Oxford University Press, 1951.

Antônio David é doutorando no Departamento de Filosofia (FFLCH), da Universidade de São, bolsista Capes.

@ - mdsf.antonio@gmail.com

Recebido em 9.4.2016 e aceito em 11.7.2016.

I Faculdade de Filosofia, Letras e Ciências Humanas, Universidade de São Paulo. São Paulo/São Paulo, Brasil. 